\title{
Penerapan Zero Waste di Pemukiman Warga Sekitar Tempat Pembuangan Akhir Sampah di Kecamatan Puuwatu, Kendari
}

\section{(Implementation of Zero Waste in Residential Areas Around the Landfill in Puuwatu Subdistrict, Kendari)}

\author{
Uli Fermin ${ }^{1}{ }^{*}$, Rahayu Endah Purwanti², Laode Muhammad Harjoni Kilowasid1, Waode Nuraida1 ${ }^{1}$, Febri \\ Dian Handayani' ${ }^{1}$, La Mudi ${ }^{1}$ \\ ${ }^{1}$ Jurusan Agroteknologi, Fakultas Pertanian, Universitas Halu Oleo, Jalan Kampus Hijau Bumi Tridharma, Anduonou, \\ Kambu, Kota Kendari, Sulawesi Tenggara 93132. \\ 2 Jurusan Penyuluhan Pertanian, Fakultas Pertanian, Universitas Halu Oleo, Kampus Hijau Bumi Tridharma, Anduonou, \\ Kambu, Kota Kendari, Sulawesi Tenggara 93132. \\ *Penulis Korespondensi: ulifermin90@uho.ac.id \\ Diterima Agustus 2018/Disetujui Desember 2019
}

\begin{abstract}
ABSTRAK
Sampah merupakan sumber masalah, jika tidak dikelola dengan baik akan menimbulkan pencemaran lingkungan, khususnya di pemukiman warga yang tinggal di sekitar Tempat Pembuangan Akhir (TPA) sampah di Kecamatan Puuwatu. Tujuan kegiatan pengabdian kepada masyarakat ini adalah mengurangi tumpukan limbah di TPA kecamatan Puuwatu melalui penerapan prinsip zero waste, yaitu dengan cara mengolah sampah padat organik menjadi kompos, lindi menjadi larutan mikroorganisme dekomposer, dan mendaur kembali sampah anorganik untuk media vertikultur. Kegiatan yang telah dilakukan untuk mencapai tujuan Program Kemitraan Masyarakat (PKM) adalah melalui penyuluhan secara massal dan kelompok kepada mitra, pelatihan, dan demonstrasi plot. Melalui kegiatan tersebut, mitra yang bermukim di sekitar TPA telah mampu mengolah sampah padat organik, dengan harapan volumenya di TPA semakin berkurang, dan pendapatan mitra meningkat. Mitra yang terlibat aktif dalam kegiatan telah mampu memproduksi kompos (diberi label KomsaMitra) yang siap untuk dikomersialkan, dan juga mampu mengolah lindi sebagai sumber mikroorganisme dekomposer (diberi label mollin). Mitra sekitar TPA Puuwatu juga mampu memanfaatkan limbah wadah berbahan plastik dan karet menjadi wadah budi daya sayuran dengan sistem vertikultur di pekarangan rumah untuk dan hasil panen sayurannya digunakan untuk memenuhi kebutuhan nutrisi keluarga.
\end{abstract}

Kata kunci: kompos, vertikultur, zero waste

\section{ABSTRACT}

Waste is a source of problems, if not managed properly it will cause environmental pollution, especially in residential settlements that live around landfills in Puuwatu District. The purpose of this community service activity is to reduce the pile of waste in the Puuwatu sub-district landfill through the application of the principle of zero waste, namely by processing organic solid waste into compost, leachate into a decomposer microorganism solution, and recycling inorganic waste for verticulture media. Activities undertaken to achieve the objectives of the Community Partnership Program (PKM) are through mass and group counseling to partners, training and plot demonstrations. Through these activities, partners who live around the landfill had been able to process organic solid waste, with the hope that the volume at the landfill will decrease, and the partner's income will increase. Partners who were actively involved in the activity had been able to produce compost (labeled Komsa-Mitra) that was ready to be commercialized, and are also able to process leachate as a source of decomposer microorganisms (labeled mollin) in the composting process. Partners around the Puuwatu landfill were also able to utilize waste plastic and rubber containers into a vegetable cultivation container with a verticulture system in the yard and the hervested vegetable was used to meet the family's nutritional needs.

Keywords: compost, verticulture, zero waste 


\section{PENDAHULUAN}

Sampah merupakan produk samping dari aktivitas masyarakat yang merupakan hasil sisa dari produk yang dianggap tidak memiliki manfaat, sehingga hasil sisa tersebut dibuang atau tidak digunakan kembali (Widawati et al. 2014). Sampah juga merupakan semua buangan yang dihasilkan oleh aktivitas manusia ataupun hewan yang berbentuk padat ataupun cair. Sampah selama ini dikenal sebagai barang yang tidak memiliki nilai bahkan dianggap sebagai barang tidak bermanfaat dan selalu dianggap sebagai sumber penyakit dan masalah terhadap lingkungan. Namun, pada kenyataannya hasil olahan sampah baik organik maupun anorganik sangat bermanfaat dalam meningkatkan kesejahteraan masyarakat bahkan dapat menjadi lahan bisnis (Karlaitè 2013).

Sampah yang masuk di TPA Puuwatu setiap hari berkisar antara 130-140 $\mathrm{m}^{3}$, dan meningkat hingga $20-25 \%$ pada hari raya keagamaan (Zonasultra 2017). Setiap hari masyarakat Kendari akan terus memproduksi sampah, sehingga jika TPA tidak mengelola sampah dengan baik akan berdampak terhadap penumpukkan sampah, selanjutnya akan terjadi pencemaran lingkungan seperti udara dan air, akhirnya akan berdampak pada kesehatan masyarakat yang bermukim di sekitar TPA Kecamatan Puuwatu.

Supaya tidak terjadi penumpukkan sampah di TPA Kecamatan Puuwatu, melalui kegiatan pengabdian kepada masyarakat dilakukan pencegahan dengan penerapan prinsip zero waste. Pengelolaan sampah secara zero waste merupakan pengelolaan dengan melakukan pemilahan, pengomposan, dan pengumpulan barang layak jual (Widiarti 2012). Kelompok masyarakat yang bermukim di sekitar TPA Puuwatu hanya memulung sampah berupa plastik dan logam, yang selanjutnya dijual kepada penampung dengan harga rendah. Sementara itu, sampah organik dan material lainnya dibiarkan begitu saja untuk diuruk. Padahal sampah organik tersebut memiliki nilai ekonomi bila diolah menjadi pupuk organik kompos berkualitas yang dapat dipasarkan ke masyarakat Kota Kendari dan untuk memupuk kebun sayuran sejumlah pemulung yang juga bertani sayuran di sekitar TPA Puuwatu, sehingga pendapatan mitra dapat bertambah.

Kompos merupakan salah satu pupuk organik yang digunakan pada pertanian untuk mengurangi penggunaan pupuk anorganik.
Penggunaan kompos dapat memperbaiki sifat fisik tanah dan mikrobiologi tanah (Syam 2003). Selain kompos, lindi (cairan yang dihasilkan dari tumpukkan sampah) di TPA dapat diolah menjadi agen dekomposer yang digunakan dalam pembuatan kompos. Penelitian Widiyani et al. (2016), menunjukkan penambahan Mikroorganisme Lokal (MOL) sebanyak $5 \mathrm{~mL}$ dan lindi $25 \mathrm{~mL}$ sebagai starter pengomposan sampah organik (campuran sampah sayur dan daun kering) menghasilkan kualitas kompos terbaik dengan rasio $\mathrm{C} / \mathrm{N}$ 12,93 pada minggu ketiga, hal ini disebabkan air lindi mengandung berbagai macam bahan organik seperti nitrat, mineral, dan organisme (Ali 2011). Zero Waste juga dapat diterapkan melalui recycle dengan prinsip menunda penumpukan sampah yang sifatnya anorganik, maka lambat laun hasil atau produknya pun akan menjadi sampah kembali (Surjandari et al. 2009). Recycle dilakukan melalui pemanfaatan sampah plastik menjadi wadah tempat tumbuhnya tanaman dalam sistem bertanam secara vertikultur. Penanaman secara vertikultur dapat dilakukan dengan cara budi daya tanaman sayuran yang dapat dilaksanakan di pekarangan rumah, namun mampu memenuhi kebutuhan nutrisi keluarga (Desiliyarni et al. 2003).

Tujuan kegiatan pengabdian kepada masyarakat ini adalah mengurangi tumpukan sampah di TPA Kecamatan Puuwatu melalui prinsip zero waste, mengolah sampah organik menjadi kompos, mikroorganisme dekomposer, dan recycle sampah anorganik menjadi media vertikultur. Kegiatan ini juga dapat meningkatkan pengetahuan warga tentang pengolahan sampah dan meningkatkan pendapatan warga karena mampu memproduksi kompos dan memenuhi kebutuhan nutrisi keluarga melalui budi daya sayuran dalam sistem vertikultur di pekarangan.

\section{METODE PELAKSANAAN KEGIATAN}

\section{Lokasi Kegiatan dan Partisipan Kegiatan}

Kegiatan pengabdian ini dilaksanakan pada bulan Maret-November 2018 di TPA sampah Kecamatan Puuwatu, Kota Kendari, Provinsi Sulawesi Tenggara. Sasaran utama yang menjadi media transfer pengetahuan adalah masyarakat yang bermukim di sekitar TPA sebagai mitra. Mitra pertama terdiri atas lima kelompok rumah warga sebagai percontohan sistem budi daya vertikultur masing-masing kelompok terdiri atas lima orang ibu rumah tangga. Mitra kedua adalah 
kelompok tani, yaitu Tani Mandiri yang terdiri atas 10 orang yang dilatih mengolah sampah organik menjadi MOL dan kompos.

\section{Bahan dan Alat}

Bahan yang digunakan dalam kegiatan pengabdian masyarakat ini adalah benih bayam, kangkung, sawi, seledri, tomat, cabai, terong, limbah cucian air beras, gula merah, limbah sampah organik, lindi sampah, dan limbah sampah anorganik (botol plastik, kemasan deterjen, talang air, pipa bekas, dan ban). Alat yang digunakan adalah kereta angkut, terpal, sekop, pisau, gunting, bak perkecambahan, paku, papan, dan tali nilon.

\section{Metode Pelaksanaan}

Metode pendekatan solusi yang ditawarkan untuk menyelesaikan permasalahan mitra, yaitu melalui kegiatan non fisik dan kegiatan fisik. Kegiatan non fisik dilakukan dengan cara memberikan penyuluhan terkait manfaat menerapkan prinsip zero waste terutama dalam memelihara kesehatan lingkungan di sekitar TPA agar tidak terjadi penumpukan sampah, dan akan berdampak positif terhadap kesejahteraan masyarakat TPA Puuwatu. Kegiatan fisik dilakukan dengan cara memberikan pelatihan dan bimbingan kepada warga terkait teknik pembuatan kompos yang baik sehingga sesuai dengan SNI, pelatihan pembuatan mikroorganisme dekomposer, dan recycle sampah anorganik menjadi sistem budi daya sayur secara vertikultur. Selain itu, kegiatan fisik juga dilakukan dengan pembuatan demonstrasi plot (demplot), yaitu terdiri ayas dua demplot. Demplot pertama adalah demplot pembuatan kompos dan MOL dan demplot kedua, yaitu demplot budi daya sayuran dengan sistem vertikultur di pekarangan rumah warga.

\section{HASIL DAN PEMBAHASAN}

Kegiatan pengabdian kepada masyarakat yang dilakukan untuk meningkatkan penerapan iptek di masyarakat yang bermukim di sekitar TPA Puuwatu diharapkan dapat berimbas pada peningkatan kesejahteraan. Gambaran iptek yang diterapkan dapat dilihat pada Gambar 1.

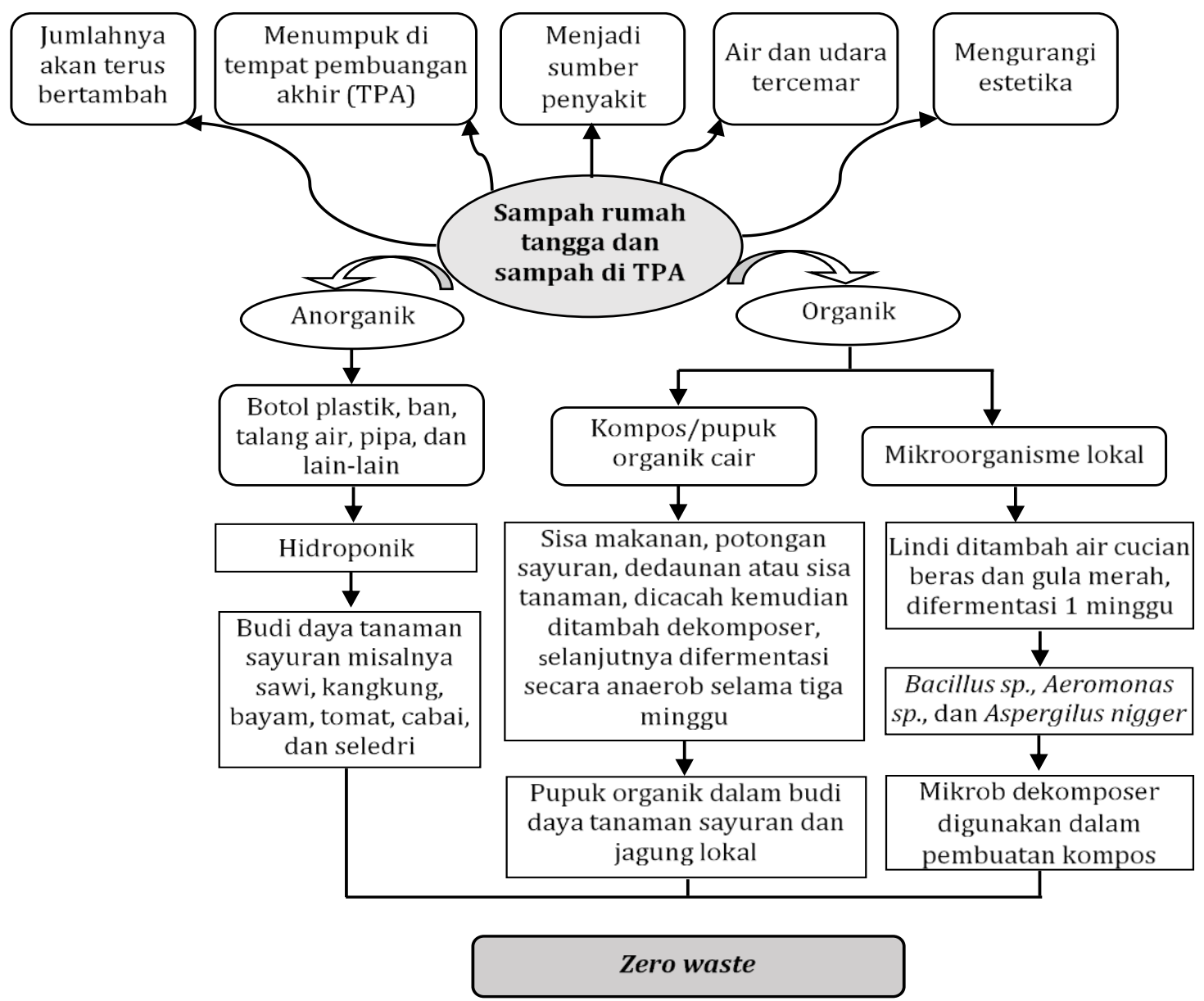

Gambar 1 Gambaran iptek yang diterapkan di tempat pembuangan akhir sampah Kecamatan Puuwatu. 


\section{Penyuluhan Penerapan Zero Waste}

Supaya iptek dapat diterapkan oleh warga sekitar TPA Puuwatu maka dilakukan penyuluhan. Metode penyuluhan pertanian dapat diartikan sebagai cara atau teknik penyampaian materi penyuluhan kepada petani baik secara langsung maupun tidak langsung, agar mereka mengetahui, berkeinginan, dan mampu menerapkan inovasi baru (Purnomo et al. 2015). Penyuluhan ini menekankan bahwa kebutuhan sayuran dapat dipenuhi dengan melakukan teknik budi daya tanaman dipekarangan oleh ibu rumah tangga, hal ini didukung oleh ketersediaan lahan pekarangan, namun belum termanfaatkan. Banyaknya lahan pekarangan yang tidak termanfaatkan disebabkan masyarakat TPA Puuwatu tidak memiliki pengetahuan dan kemampuan teknik budi daya tanaman terutama tanaman hortikultura.

Kegiatan penyuluhan (Gambar 2), bertujuan agar masyarakat tergerak untuk mandiri dalam produksi tanaman pangan maupun hortikultura. Penyuluhan yang dilakukan ini mengangkat tema kemandirian pangan melalui penerapan zero waste di pemukiman miskin sekitar TPA sampah Kecamatan Puuwatu, Kendari, Sulawesi Tenggara. Tujuan kegiatan penyuluhan ini juga memberikan pengetahuan kepada masyarakat cara mengurangi jumlah sampah di TPA adalah sebagai berikut:

- Mengolah sampah organik menjadi kompos. Sampah sisa tanaman, sayuran yang berasal dari buangan pasar, sampah serbuk kayu, kotoran ternak, dan lain-lain difermentasi dengan menggunakan MOL selama tiga minggu.

- Mengolah lindi sampah menjadi MOL, lindi sampah yang dihasilkan oleh tumpukan sampah di TPA yang tidak terkelola dengan baik dan berdampak terhadap pencemaran lingkungan dan kesehatan dapat diolah

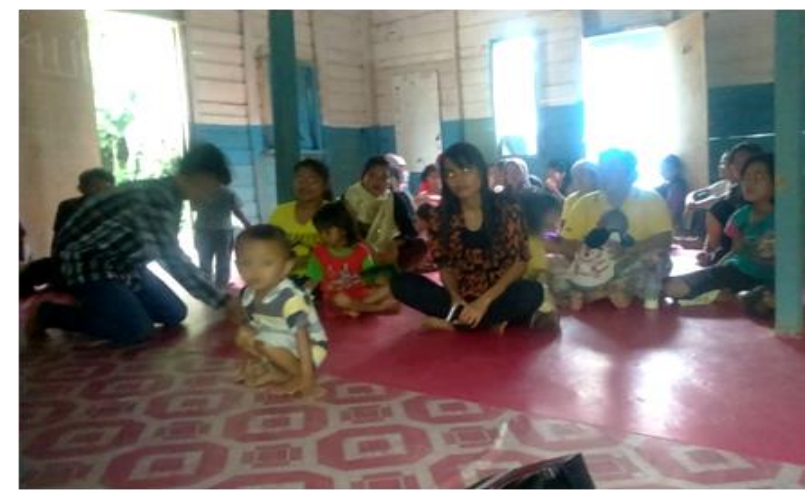

menjadi produk bermanfaat dengan cara mengaktifkan mikroorganisme yang terkandung dalam lindi, dan dapat difungsikan sebagai dekomposer dalam pembuatan kompos sampah.

- Merangkai sampah anorganik, yaitu sampah botol plastik, kemasan deterjen, dan wadah plastik dari hasil buangan di TPA menjadi wadah vertikultur yang dapat digunakan sebagai media tumbuh dipekarangan rumah warga.

\section{Pengelolaan Lindi menjadi Mikroorganisme Dekomposer}

Air lindi apabila tidak dikelola dengan baik maka akan menimbulkan dampak negatif karena mengandung zat pencemar organik dan anorganik yang tinggi (Dimiati \& Hadi 2017). Pada kegiatan PKM ini lindi dikelola menjadi produk bermanfaat, yaitu MOL yang merupakan cairan hasil fermentasi yang mengandung mikroorganisme hasil produksi sendiri. Lindi merupakan tempat yang disukai oleh mikroorganisme sebagai media untuk hidup dan berkembang yang berguna dalam mempercepat penghancuran bahan-bahan organik (dekomposer) atau sebagai tambahan nutrisi bagi tanaman (Palupi 2015). Kegiatanan pengolahan lindi sampah yang sangat berlimpah sebagai mikroorganisme lokal yang mampu berfungsi sebagai dekomposer ataupun pupuk cair dapat dilihat pada Gambar 3. MOL yang merupakan produk luaran dari kegiatan PKM ini diberi nama "mollin", yaitu MOL lindi sampah.

Prosedur pembuatan Mollin ini adalah dengan cara mengambil lindi sampah sebanyak 2 L kemudian dicampur dengan cucian air beras sebanyak $2 \mathrm{~L}$ dan gula merah sebanyak $500 \mathrm{~g}$. Larutan tersebut dihomogenkan dalam satu wadah ember kemudian ditutup rapat dengan menggunakan plastik atau difermentasikan

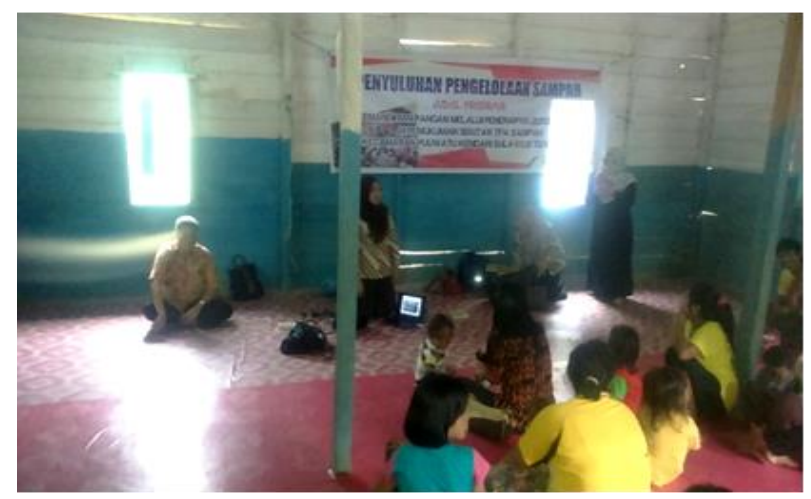

Gambar 2 Penyuluhan penerapan zero waste di pemukiman sekitar tempat pembuangan akhir sampah Kecamatan Puuwatu. 


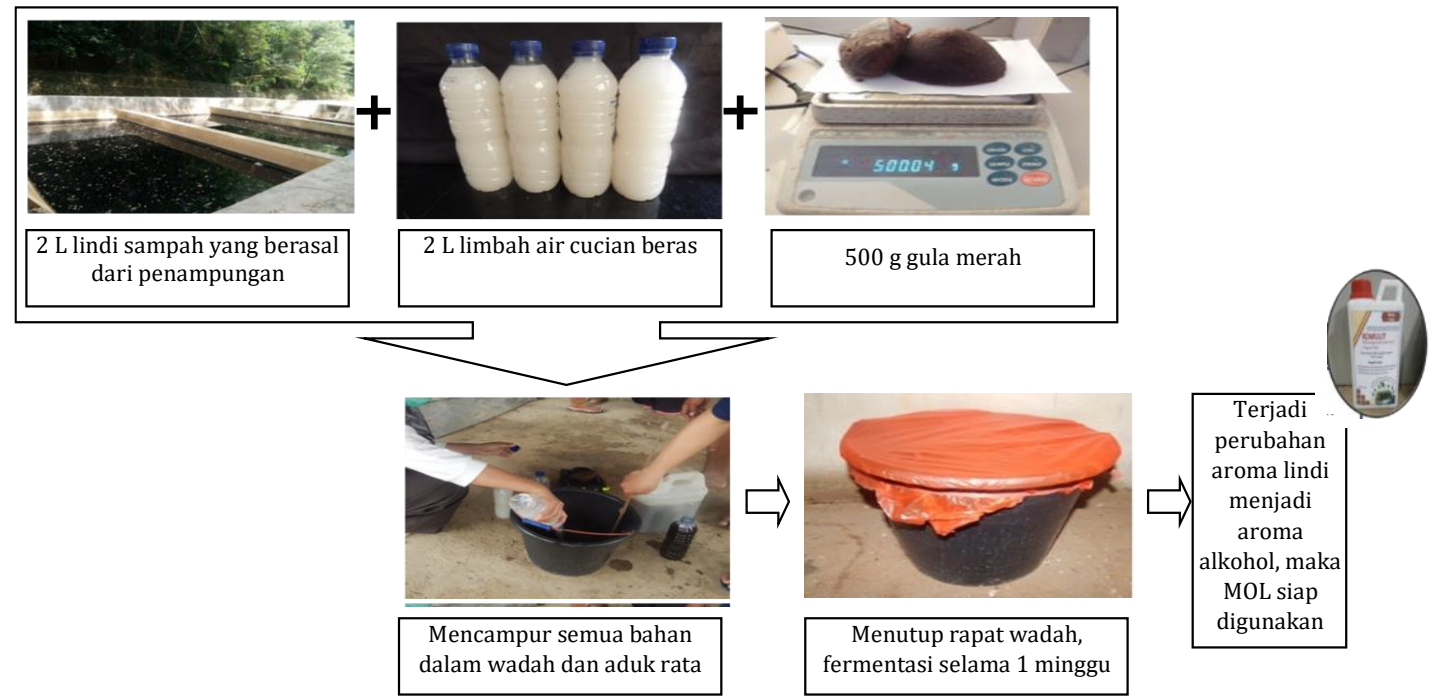

Gambar 3 Prosedur pembuatan mikroorganisme lokal (mollin) sebagai dekomposer atau pupuk cair.

selama satu minggu. Selanjutnya, terjadi perubahan aroma menjadi aroma alkohol yang menandakan bahwa mollin siap untuk digunakan sebagai dekomposer ataupun sebagai pupuk cair. Hasil penelitian Damsir et al. (2016) menyatakan bahwa melalui proses degradasi lindi, yaitu fermentasi anaerob unsur hara yang dibutuhkan tanaman $(\mathrm{N}, \mathrm{P}$, dan $\mathrm{K})$ memenuhi standar yang aman untuk dikembalikan ke lingkungan sebagai pupuk cair, sedangkan polutan dalam lindi seperti logam berat $\mathrm{Hg}, \mathrm{Cr}, \mathrm{Pb}, \mathrm{Zn}$, dan $\mathrm{Cu}$ juga memenuhi standar baku yang aman untuk dikembalikan ke lingkungan dalam bentuk pupuk cair bagi kegiatan pertanian.

\section{Pelatihan Pembuatan Kompos}

Kegiatan ini dilaksanakan pada tanggal 18 April 2018 di tempat penampungan sampah plastik di TPA, yang juga difungsikan sebagai rumah kompos. Prosedur pembuatan kompos dalam PKM ini adalah warga terlebih dahulu memisahkan sampah sayuran (sampah basah), sampah pekarangan (sampah kering), serbuk gergaji, dan kotoran kambing/sapi dengan perbandingan 1:1:1:1. Masyarakat memanfaatkan alat pencacah plastik untuk mencacah bahanbahan kompos tersebut. Setelah halus, bahanbahan tersebut dipindahkan dalam ruangan tertentu untuk dicampur kembali kemudian disiram dengan larutan mollin sebanyak $10 \%$. Bahan-bahan kompos diaduk dengan menggunakan sekop hingga setiap bagian tercampur dengan larutan mollin, setelah itu bahan tersebut difermentasikan dengan cara ditutup menggunakan plastik, dan dibuka setiap tiga hari dan diaduk. Setelah dua minggu, panas dari bahan tersebut telah hilang yang menandakan bahwa kompos telah siap digunakan, ayak kompos selanjutnya dikemas dan siap pula untuk dikomersialkan. Kompos yang dihasilkan dalam kegiatan ini akan menjadi produk luaran kegiatan PKM yang di beri label dengan nama KomsaMitra. Adapun prosedur pembuatan kompos dalam kegiatan pengabdian masyarakat ini dapat dilihat pada Gambar 4.

\section{Budi Daya Tanaman Sayuran dalam Sistem Vertikultur}

Sistem budi daya tanaman hortikultura secara vertikultur dapat mengurangi peningkatan sampah misalnya botol plastik, wadah plastik, dan kemasan deterjen plastik. Selain itu, sistem vertikultur merupakan bentuk pemanfaatan lahan pekarangan yang mengandung nilai estetika (Gambar 5). Warga yang berprofesi sebagai ibu rumah tangga di TPA Kecamatan Puuwatu sebagaian besar tidak memiliki pengetahuan yang memadai terkait teknik budi daya tanaman. Budi daya vertikultur ini juga memanfaatkan Komsa-Mitra sebagai suplay hara terhadap pertumbuhan tanaman.

Pemanfaatan sampah anorganik merupakan kegiatan recycle yang bertujuan untuk mengurangi penumpukan sampah di TPA. Affandi et al. (2015) menyatakan sampah anorganik merupakan limbah yang sangat sulit terurai. Budi daya tanaman sayuran dalam sistem vertikultur sangat membantu warga dalam memenuhi kebutuhan nutrisi keluarga, yaitu sayuran segar (Desiliyarni et al. 2003), namun warga kesulitan dalam mendapatkan benih untuk melakukan budi daya sehingga perlunya dukungan pemerintah untuk dapat menyalurkan benih kepada masyarakat di sekitar TPA. 


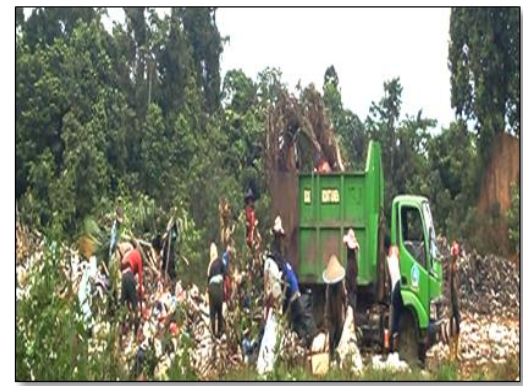

a

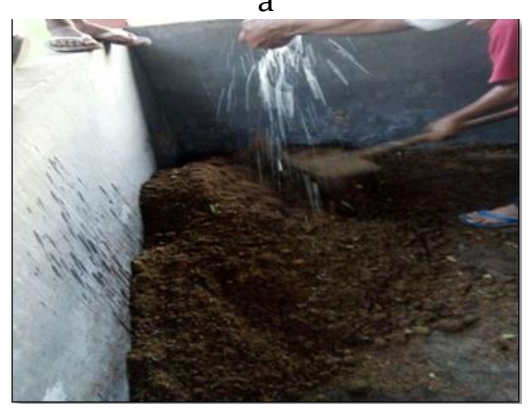

d

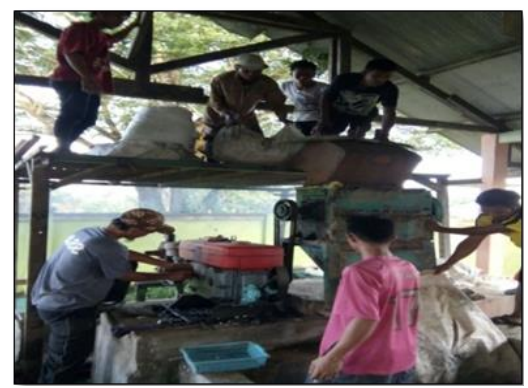

$\mathrm{b}$

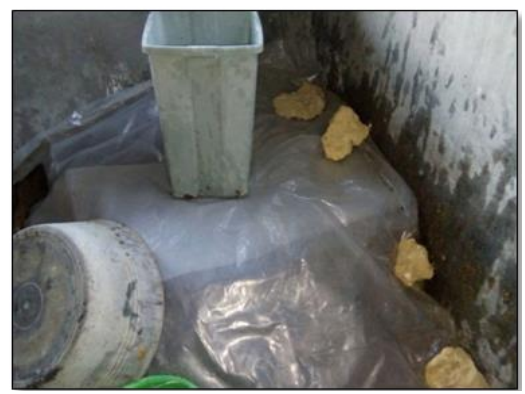

$\mathrm{e}$

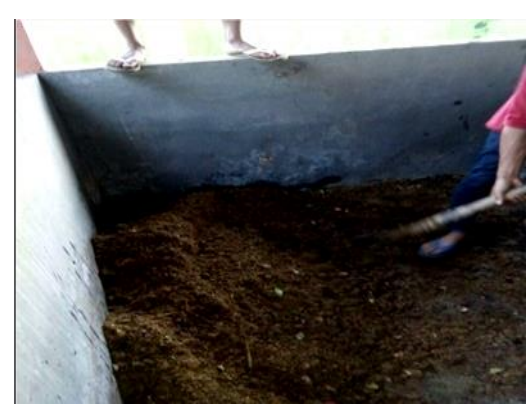

c

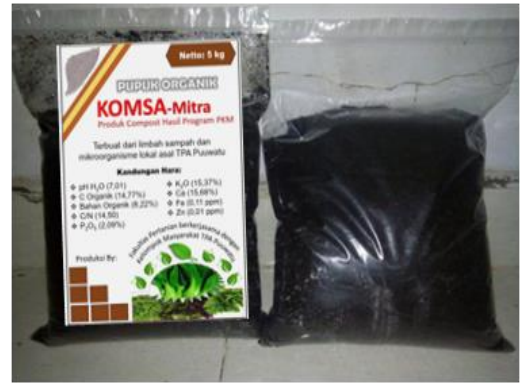

f

Gambar 4 Prosedur pembuatan kompos sampah yang selanjutnya diberi nama Komsa-Mitra; a) Pemilahan sampah; b) Pencacahan dengan mesin; c) Pengadukan hasil cacahan; d) Pencampuran dengan mollin; e) Proses fermentasi; dan f) Hasil kompos setelah dua minggu.
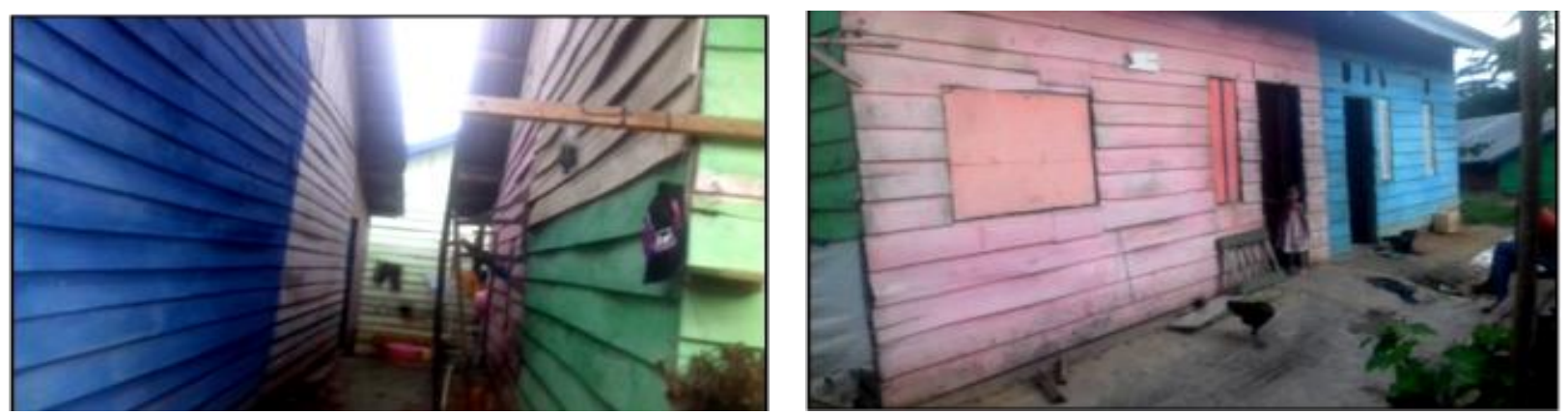

a
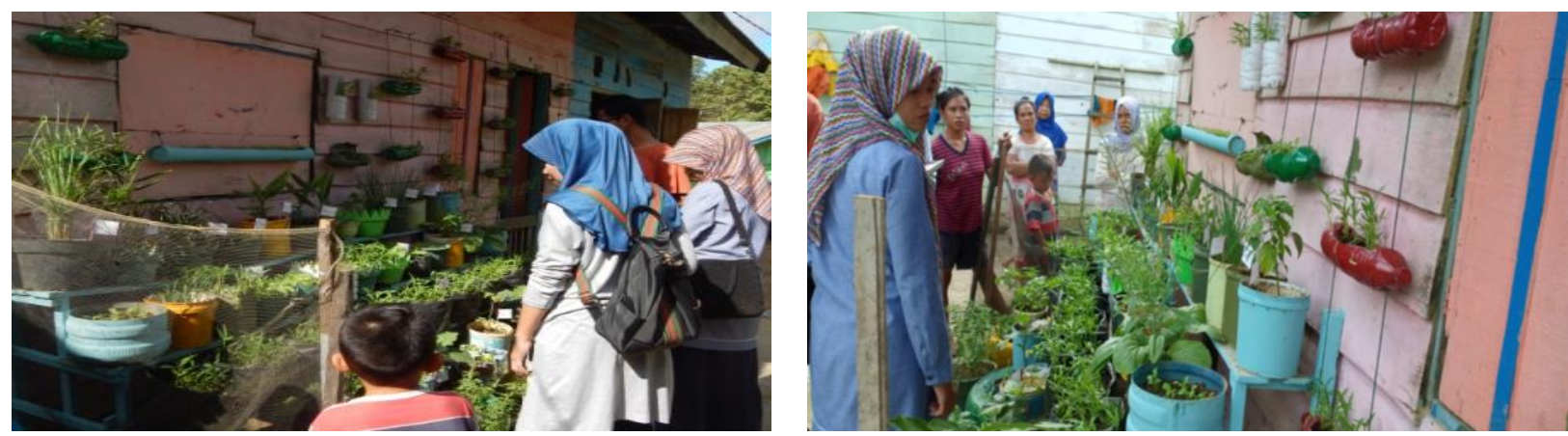

b

Gambar 5 Kondisi pekarangan warga sekitar tempat pembuangan akhir sampah Kecamatan Puuwatuu sebelum (a) dan sesudah (b) pelatihan budi daya tanaman sayuran secara vertikultur.

\section{SIMPULAN}

Kegiatan PKM ini dapat menambah wawasan bagi masyarakat sekitar TPA Puuwatu, tentang cara mengolah sampah menjadi barang bernilai ekonomi sehingga dapat mengurangi penum- pukan sampah. Melalui kegiatan PKM ini warga mampu membuat kompos yang diberi nama produk Komsa-Mitra dan hasil kompos yang dibuat warga memiliki kandungan hara sesuai SNI kompos layak pakai. Warga mampu membuat mikroorganisme lokal yang berasal dari lindi 
yang diberi nama produk mollin. Selain itu, warga mampu memenuhi kebutuhan sayuran segar melalui budi daya tanaman hortikultura secara vertikultur yang diaplikasikan dengan KomsaMitra. Saran dari tim terhadap keberlanjutan kegiatan ini perlu adanya dukungan pemerintah agar masyarakat ditekankan dapat selalu hidup sehat dan mampu memanfaatkan serta mengelola sampah agar tidak memberikan dampak negatif.

\section{UCAPAN TERIMA KASIH}

Penulis mengucapkan terima kasih kepada Kementerian Riset Teknologi dan Pendidikan Tinggi serta Lembaga Penelitian dan Pengabdian Masyarakat, Universitas Halu Oleo yang telah mendanai pengabdian ini melalui DP2M pendanaan tahun 2018, sehingga penulis dapat melaksanakan kegiatan pengabdian masyarakat ini melalui kegiatan Program Kemitraan Masyarakat (PKM) di Kecamatan Puuwatu, Kendari, Sulawesi Tenggara.

\section{DAFTAR PUSTAKA}

Affandi NA, Isnaini E, Yulianti CH. 2015. Peran Serta Masyarakat dalam Pengelolaan Sampah Komprehensif Menuju Zero Waste. Dalam: Seminar Nasional Sains dan Teknologi Terapan III. Surabaya (ID): Institut Teknologi Adhi Tama Surabay. Page: 803-814.

Ali M. 2011. Rembesan Air Lindi (Leachate) Dampak pada Tanaman Pangan dan Kesehatan. Surabaya (ID): Universitas Pembangunan Nasional Veteran.

Damsir, Suprihatin, Romli M, Yani M, Herlambang A. 2016. Karakteristik Lindi Hasil Fermentasi Anaerobik Sampah Kota dalam Lisimeter dan Potensi Pamanfaatannya Menjadi Pupuk Cair. Jurnal Teknologi Industri Pertanian. 26(2): 125-133.

Desiliyarni T, Astuti Y, Fauzy F, Endah J. 2003. Memanfaatkan Rumah dan Pekarangan Vertikultur Teknik Bertanam di Lahan Sempit. Jakarta (ID): Agromedia Pustaka. Page: 22.

Dimiati DD, Hadi W. 2017. Uji Pemanfaatan Pupuk Organik Cair Lindi dengan
Penambahan Bakteri Starter Terhadap Pertumbuhan Tanaman Hortikultura (Solanum Melongena dan Capsicum Frutescens). Jurnal Teknik ITS. 6(2): 2337$3539 . \quad$ https://doi.org/10.12962/ j23373539.v6i2.25199

Karlaitė D. 2013. Waste Management-The Future of Prosperous Socially Responsible Business. In Proceedings: $3^{\text {rd }}$ International Scientific Conference "Practice and Research in Private and Public Sector. Page: 82-89.

Palupi NP. 2015. Ragam Larutan Mikroorganisme Lokal sebagai Dekomposer Rumput Gajah (Pennisetum purpureum). Jurnal Ziraa'ah. 4(2): 123-128.

Purnomo EN, Pangarsa KB, Andri, Saeri M. 2015. Efektivitas Metode Penyuluhan dalam Percepatan Transfer Teknologi Padi di Jawa Timur. Jurnal Inovasi dan Teknologi Pembelajaran. 1(2): 192-204.

Surjandari I, Hidayanto A, Supriatna A. 2009. Model Dinamis Pengelolaan Sampah untuk Mengurangi Beban Penumpukan. Jurnal Teknik Industri. 11(2): 134-147.

Syam A. 2003. Efektivitas Pupuk Organik dan Anorganik terhadap Produktivitas Padi di Lahan Sawah. Jurnal Agrivigor. 3 (2): 232-244.

Widawati E, Tanudjaja H, Iskandar I, Bidiono C. 2014. Kajian Potensi Pengolahan Sampah (Studi Kasus: Kampung Banjarsari). Jurnal Metris. 5(2014): 119-126. https://doi.org/10. 20885/jstl.vol4.iss2.art4

Widiarti IW. 2012. Pengelolaan Sampah Berbasis "Zero Waste" Skala Rumah Tangga Secara Mandiri. Jurnal Sains dan Teknologi Lingkungan. 4(2): 101-103.

Widiyani S, Oktiawan W, Zaman. 2016. Pengaruh Penambahan Lindi dan Mol Tapai Terhadap Waktu Pengomposan. Jurnal Teknik Lingkungan. 5(4): 1-9.

Zonasultra. 2017. Selama Ramadhan Volume Sampah di Kendari Meningkat 20\% per Hari. [Internet]. [diunduh 10 Agust 2018]. Tersedia pada: https://zonasultra.com/selamaramadhan-volume-sampah-di-kendarimeningkat-20-persen-perhari.html 